\title{
SLEEP QUANTITY AND QUALITY AND CARDIO-METABOLIC RISK FACTORS IN INDIGENOUS AUSTRALIANS
}

\author{
Yiallourou SR ${ }^{1}$, Maguire $\mathrm{GP}^{1,2}$, Carrington $\mathrm{MJ}^{1}$ \\ ${ }^{1}$ Baker Heart and Diabetes Institute, Melbourne, Australia. \\ ${ }^{2}$ General Internal Medicine, Western Health, Melbourne, Australia
}

Subtitle: Sleep and cardio-metabolic risk

\section{Correspondence:}

Dr Stephanie Yiallourou

Pre-Clinical Disease and Prevention, Baker Heart and Diabetes Institute, Melbourne, Australia Email: stephanie.yiallourou@baker.edu.au

75 Commercial Rd, Melbourne, Victoria 3004 Australia Telephone: +61385321744

\begin{abstract}
:
Poor sleep is associated with increased risk of cardiovascular disease. Indigenous Australians have 1.3 times higher risk of cardiovascular disease compared to non-Indigenous Australians. However, there are limited data describing sleep problems and cardio-metabolic risk in this population. This study aimed to investigate sleep quantity and quality in Indigenous Australians and assess its association with cardio-metabolic risk.

245 Indigenous Australians aged $>18$ years were recruited via convenience sampling from communities in Northern Territory and Queensland. Sleep quantity and quality was assessed subjectively with questionnaires including the Epworth Sleepiness Scale. In a sub-population $(\mathrm{n}=46)$, objective sleep assessment was performed over 3 nights of actigraphy. Cardiometabolic risk measures included glycated haemoglobin, lipids, anthropometric measurements and sitting blood pressure.

Sleep duration measured subjectively and objectively averaged 7.5 $\pm 2.0 \mathrm{~h} /$ night, however over one-third of participants (self report 35\%, actigraphy 39\%) obtained $<7 \mathrm{~h} /$ night. Overall, more

This is the author manuscript accepted for publication and has undergone full peer review but has not been through the copyediting, typesetting, pagination and proofreading process, which may lead to differences between this version and the Version of Record. Please cite this article as doi: 10.1111/ISR.13067
\end{abstract}

This article is protected by copyright. All rights reserved 
than a third of participants experienced poor quality sleep, with $27 \%$ reporting severe daytime sleepiness (ESS score $>10$ ) and a high number of objectively measured awakenings/night (6 \pm 4 ). Short sleep duration $(<6 \mathrm{~h} /$ night $)$ measured both subjectively and objectively was an independent predictor of diastolic $(\beta=5.37, p=0.038)$ and systolic blood pressure $(\beta=14.30$, $\mathrm{p}=0.048$ ), respectively. More objectively measured night-time awakenings were associated with increased glycated haemoglobin levels $(\beta=0.07, \mathrm{p}=0.020)$ and greater sleep fragmentation was associated with lower high density lipoprotein levels $(\beta=-0.01, p=0.025)$.

A large proportion of Indigenous Australians experienced short sleep durations and had significant sleep disruption. Poor sleep quantity and quality may contribute to heightened cardio-metabolic risk in this population.

Keywords: sleep, cardio-metabolic risk, Indigenous Australian, cardiovascular disease, Aboriginal and Torres Strait Islander people, metabolic syndrome

\section{INTRODUCTION:}

A gap in life expectancy of up to 21 years exists between Indigenous and non-Indigenous people (WHO, 2007), which is thought to be attributed to a higher prevalence of cardiovascular disease (CVD) in higher income countries (AIHW, 2015). In the context of cardio-metabolic health, disparities in health driven by social inequality, colonization, historical trauma and discrimination have negatively impacted diet and levels of physical activity/sedentary time and are thought to be major determinants in the development of CVD in Indigenous people. These factors, alongside psychosocial health and well-being are believed to contribute to heightened risk of cardio-metabolic diseases in vulnerable population groups (Gray C, 2012).

A number of policies and programs are currently working towards improving cardio-metabolic health outcomes in Indigenous populations in countries which have arisen from European colonization. However, despite these efforts, life expectancy still remains lower in Indigenous people. In order to close the gap in health equity, better models for risk prevention with novel targets are needed to identify individuals at higher risk and improve management to enhance health outcomes.

Poor sleep has been proposed to play a role in increased cardio-metabolic risk. Poor sleep, whether it be short sleep duration or fragmented sleep, is associated with higher risk for metabolic syndrome (Killick, Banks, \& Liu, 2012) and CVD (Floras, 2018). Short sleep duration has multiple negative cardio-metabolic health outcomes such as increased risk of hypertension, glucose intolerance, hypercholesterolemia (St-Onge et al., 2016). 
Indigenous populations in high income countries have increased risk of sleep problems compared to non-Indigenous populations (Redline \& Tishler, 2000). Studies in the United States (Sabanayagam, Shankar, Buchwald, \& Goins, 2011) and New Zealand (Paine, Harris, Cormack, \& Stanley, 2017) suggest that short sleep duration and sleep problems, respectively are associated with increased risk of CVD in Indigenous populations. These studies are limited however, as all have utilized subjective measures of sleep rather than objective measures and few have performed clinical assessment of cardio-metabolic risk profiles. Furthermore, data in Indigenous Australian adults is particularly lacking. In Australia, CVD is the leading cause of death in Indigenous Australians (AIHW, 2015). Based on self-report data 35\% of Indigenous Australians experience sub-optimal sleep quantity (defined as sleeping $<7$ hours per day or sleeping $>9$ hours per day) compared to $21 \%$ in non-Indigenous Australians (Macniven et al., 2016). However, to date no study has investigated the link between poor sleep and cardiometabolic risk factors in Indigenous Australian adults.

Accordingly, as part of the BIRCH study (Better Indigenous Risk Stratification for Cardiac Health) we aimed to assess: 1) Sleep quantity and quality using subjective and objective measures of sleep; 2) The environmental, lifestyle and biological determinants of sleep and 3) The contribution of poor sleep at night (quantity and quality) to cardio-metabolic risk in Indigenous Australian adults. Similar to Indigenous populations in other high income countries, we hypothesized that Indigenous Australians would experience poor sleep quantity and quality at night and that poor sleep is associated with increased cardio-metabolic risk.

\section{METHODS:}

\section{Study design}

Detailed procedures of the BIRCH study design can be found in the published protocol (Remond et al., 2017). Participants were recruited as part of the BIRCH study, a large multisite study to better identify CVD risk factors in Indigenous Australians. BIRCH was a crosssectional and prospective observational cohort study of Aboriginal and Torres Strait Islander (Indigenous) aged over 18 years and living in remote Australia. In brief, participants were assessed for traditional CVD risk factors and sleep quantity and quality. For the purposes of this paper, data on sleep measures and associations with traditional CVD risk factor data will only be presented. The study was approved by the Australian Catholic University Human Research Ethics Committee (Project No. 2014 244V), Central Australian Human research 
Ethics Committee (HREC-15-355) and the Townsville Hospital and Health Service Human Research Ethics Committee (HREC/16/QTHS/46, SSA/16/QTHS/173). Ethics approval involved consultation with local community, health and other stakeholders as well as consideration of local cultural issues. Written informed consent was obtained from all participants prior to the study initiation.

\section{Procedures}

In total, 245 participants were recruited to the study which was carried out in three mobile clinics in Alice Springs, Katherine and Palm Island between 2016 and 2018 (Figure 1). BIRCH was performed out of either an Aboriginal-led health service regional clinic in addition to a mobile health van which travelled out to surrounding town camps (closed communities where Aboriginal people reside and a place where Aboriginal people visit from remote areas and can stay for short periods) in regional/remote Australia. Recruitment of participants was performed by a convenience sampling method and following written informed consent. A local Aboriginal health researcher recruited individuals within and nearby areas of the clinics and all cardiometabolic risk assessments were performed on the same day of recruitment. All participants underwent a CVD risk assessment including 1) anthropometric and point of care measures (blood glucose, triglycerides, cholesterol, lipids) and, 2) face-face questionnaires to assess sleep quantity and quality. Participants who agreed to take part in an objective sleep assessment underwent 2-3 day/night of actigraphy. At the time of the assessment, participants were provided with general feedback regarding their CVD risk profile based on existing Australian guidelines [57-61] and information regarding potential lifestyle changes that may reduce any potential risk.

\section{Study variables and data collection procedures}

\section{Structured questionnaires}

Structured questionnaires were completed and collected information on socio-demographic indicators including age, sex and ethnicity; lifestyle factors including smoking and alcohol; and brief medical history.

\section{Anthropometry and biomedical risk factors}

During the clinic assessment, anthropometric outcomes of height, weight, BMI and waist circumference were collected. Blood biochemistry was assessed using capillary/fingerstick whole blood tests of lipid (total [TC], high [HDL] and low [LDL] density lipoprotein cholesterol and triglycerides) and glycaemic (HbAlc) measurements via a point of care 
analyser (Afinion ${ }^{\mathrm{TM}}$ AS100, Alere, MA, USA). Sitting blood pressure (BP) was measured twice with a 5 minute rest period in between each measurement using an automated BP monitor (Omron HEM-907, Omron Healthcare Co. Ltd, Kyoto, Japan).

\section{Sleep questionnaires}

Self report sleep quantity and quality was assessed via a sleep study questionnaire based on three themes: sleep quantity and quality, sleeping environment and potential determinants of poor sleep. The Epworth Sleepiness Scale (ESS) assessed daytime sleepiness, with scores $\geq 10$ considered to reflect significant sleepiness associated with a sleep disorder (Johns, 1992). Participants completed the questionnaire via face-face interview with a trained research assistant. The sleep study questionnaire also included questions about sleep quality (e.g., participants were asked to rate their sleep on a scaled score of 1-5 (5=Excellent and $1=$ Poorly/Badly) with scores $\leq 2$ indicating poor sleep quality); estimated sleep parameters (e.g., sleep duration, day-time nap duration, sleep onset latency, no. of awakenings/night), potential sleep disorders (e.g., sleep-disordered breathing, Do you snore at night?, Do you sometimes stop breathing when asleep?) sleeping environment (e.g.; How many people usually sleep in the same room as you?) and other potential causes of sleep disruption (e.g. smoking, caffeine and alcohol intake).

\section{Actigraphy}

Actigraphy is a widely accepted and validated for assessment of the sleep/wake cycle (AncoliIsrael et al., 2003). To assess sleep objectively, 2-3 day/night actigraphy (GT3x actigraphy device, Actigraph ${ }^{\mathrm{TM}}$. Pensacola, Florida, USA) was offered to each participant. Up to three day/night was specifically chosen to optimise recording time and return of the actigraph monitor whilst still present in the community. The GT3x was worn on the hip of participants along the mid axillary line and measured 24-h activity levels in 60 second epochs (Barreira et al., 2018). These methodologies and the device type were chosen for a number reasons. There are inherent barriers to research in Indigenous Australian communities, particularly with recruitment, retention and adherence to study programs. Longitudinal studies can be challenging as often Indigenous Australians move between different places, moving to different houses within the community or even travelling to different communities to reside, making loss-to-follow-up more than expected compared to non-Indigenous populations (Gubhaju et al., 2016). Moreover, attending medical clinics and wearing medical devices (such as polysomnography equipment or even actigraphy devices) are commonly avoided as they can be sometimes viewed as a sign of shame, potentially affecting recruitment and possible weartime even if participants consent to the study. The relatively low cost GT3x was utilised as we 
anticipated a high number of device loss due to the higher loss-to-follow-up inherent in this population. Furthermore, the GT3x can be worn comfortably around the hip and covered by clothing (even in the hot and humid climates of the communities studied) to avoid the stigma of shame. While these devices are not as accurate as wrist worn sleep monitors (Full et al., 2018), we selected a device that was practicable, inexpensive and culturally acceptable and sensitive.

The analysis of actigraphy data was performed according to a standardised protocol by the same trained independent researcher using specialised software (Actilife 6.8.1, Actigraph ${ }^{\mathrm{TM}}$, Pensacola, Florida, USA). SBSM guidelines were followed (Ancoli-Israel et al., 2015) for actigraphy review and scoring. All participants were provided with sleep diaries, however, not all were able to complete them. Accordingly, all epochs were manually reviewed by hand scoring in- and out-of-bedtimes and manually scoring any anomalous epochs, which were excluded. Sleep quality and quantity was assessed via the following parameters for a minimum of 2 nights: total sleep time (TST, hrs), wake after sleep onset (WASO, min), number of awakenings, sleep onset latency (SOL, min) and sleep fragmentation index (SFI, the percentage of epochs with vertical axis counts greater than zero in the sleep period + the percentage of 1min periods of sleep versus all periods of sleep during the sleep period, reflecting microarousals during sleep). A mean value was calculated across the 2-3 day/night for each participant for each sleep measure. Short sleep durations were defined as $<6 \mathrm{~h} /$ night (Tobaldini et al., 2019) and long sleep duration as $>9$ h/night (Gottlieb et al., 2006), based on previous studies showing associations with sleep duration and CVD risk. Significant sleep fragmentation was defined as WASO >30 minutes (Bathgate, Edinger, \& Krystal, 2017) and >3 awakenings/night (Natale, Plazzi, \& Martoni, 2009; Ohayon, Krystal, Roehrs, Roth, \& Vitiello, 2010).

\section{STATISTICAL ANALYSIS:}

Analyses were undertaken using IBM SPSS Statistics version 22.0 (IBMCorp, Armonk, NY, USA). $p<0.05$ defined statistical significance. Descriptive statistics were used to summarise the demographic and clinical profile of the cohort. Continuous variables are expressed as mean \pm standard deviation (SD). Categorical data are expressed as percentages. Continuous variables were compared using Students T-tests for parametric data and Mann Whitney U test for nonparametric data. Categorical data were analysed via $\chi^{2}$ analysis.

To determine predictors (environmental, lifestyle and biological) of sleep and predictors (sleep quantity and quality) of cardio-metabolic risk factors, multiple backward stepwise regression 
analysis was performed. Where adjustment for covariate(s) was required, co-variates (e.g age, gender, BMI, smoking, diabetes) were entered first in a hierarchical model and predictors were entered second to examine independent associations of risk factors.

\section{RESULTS:}

In total, 245 participants completed both the sleep study questionnaires and underwent cardiometabolic risk assessment. Of these, 65 agreed to have an actigraphy recording. Actigraphic recordings were successful in 46 participants, with 9 monitors never returned, 3 with technical faults and 7 with insufficient wear-time.

\section{Cardio-metabolic risk and sleep measures}

Cardio-metabolic risk and sleep measures are summarised in Table 1 according to gender and region. Overall, the average age of participants was $45 \pm 13$ years with slightly more women compared to men ( $57 \%$ women vs $43 \%$ men). The overall cohort had higher than normal BMI $\left(28 \pm 6 \mathrm{~kg} / \mathrm{m}^{2}\right)$ which was lower in men than women. Approximately one in four reported diabetes $(27 \%)$ and two in three were current smokers $(65 \%)$, with a higher proportion of smokers in Northern Territory. SBP was $8 \mathrm{mmHg}$ higher in males compared to females $(\mathrm{p}=0.005)$. Alcohol intake/day and HDL levels were lower and LDL levels were higher in Queensland compared to Northern Territory participants.

Both subjective and objective measures of sleep quantity and quality are summarised in Table 1. Of the 245 interviewed, $n=126$ self-reported sleep duration. Average sleep duration for both subjective and objective measures was within normal limits ( 7.5 hours/night), however approximately one-third (35\% self-report and 39\% actigraphy) had $<7$ hours/night. Poor sleep quality was reported in over half of the cohort, with 58\% scoring their sleep as sub-optimal (sleep quality score $<2$ ). Just over half the cohort reported snoring and almost $20 \%$ reported apnoea during the night. Participants reported a long SOL, with average time to fall asleep $>30$ minutes. Over a quarter of participants reported significant sleep disruption having $\geq 3$ awakenings/night, which was also reflected in the objective measures averaging 6 awakenings/night. Almost a quarter had $\geq 30 \mathrm{~min}$ of WASO and over one-third had a high SFI. Average daytime sleepiness measures were within normal limits, however 27\% scored an ESS of $\geq 10$.

Females reported a higher percentage of poor sleep quality and awakenings compared to males. North Queensland participants had lower subjective daytime sleepiness (assessed by the ESS 
$\geq 10$ ), no. awakenings and morning tiredness/fatigue compared to Northern Territory participants.

\section{Sleeping Environment and potential barriers to sleep}

Figure 2 illustrates the sleeping environment and drinking habits of caffeinated and alcoholic beverages before bed. One third of participants shared a bed with $>2$ persons (Fig 2A) and almost a quarter shared the same room with $>3$ persons (Fig 2B). The majority slept on a bed/bunk (Fig 2C) and almost one third reported a physical complaint that disrupted their sleep (most commonly back and neck pain and muscular cramps) (Fig 2D). Between 8-15\% had more than 4 cups of tea or coffee/day and over one third had 1 or more $370 \mathrm{ml}$ cans of cola/day (Fig 2E-G). Furthermore, 14\% consumed $>2$ standard alcoholic drinks/day (Fig 2H).

\section{Determinants of sleep quantity and quality}

Table 2 summarises the environmental, lifestyle and biological determinants of sleep quantity and quality. Of the environmental determinants only region was a significant determinant of sleep, with the North Queensland region associated with lower ESS scores.

Smoking was a predictor of shorter objective sleep duration, such that current smoking equated to 65 minutes less sleep compared to non-smoking. Higher daily alcohol intake predicted a higher ESS score and a higher intake of caffeinated drinks/day was associated with higher selfreport awakenings.

Older age was associated with lower self-report sleep quality and a higher number of awakenings per night. Female gender predicted poorer self-report sleep quality and higher amounts of awakenings/night, but male gender predicted higher SFI. For pathological conditions, diabetes was associated with higher self-reported awakenings, but a reduced number of awakenings and SFI recorded objectively. Self-report apnoea was associated with lower subjective sleep quality and higher ESS scores. Physical complaints were associated with poor sleep quality, a number of awakenings and increased ESS scores all by self-report.

\section{Predictors of cardiometabolic risk}

Table 3 shows the significant clinical and sleep determinants of cardiometabolic risk factors. The variables analysed predicted between 10 to $67 \%$ of the variance of risk factors assessed. Older age predicted higher SBP, DBP, TC, HDL and triglyceride levels. Male gender was associated with higher SBP, TC and LDL levels. Higher BMI predicted higher DBP and 
triglyceride levels. Diabetes predicted higher HbA1c \%, but lower levels of TC, LDL and HDL levels.

Overall, sleep measures were independently associated with BP, $\mathrm{HbA} 1 \mathrm{c} \%$ and cholesterol levels. Participants who had short sleep duration ( $<6$ hours/night) had higher DBP by selfreport and SBP by objective measures. Of note, having $<6$ hours/night equated to a $\sim 14 \mathrm{mmHg}$ increase in SBP compared to having $>6$ hours sleep/night assessed objectively. Sleep disruption also contributed to cardiometabolic risk factors, with a higher objective no. awakenings at night associated with higher $\mathrm{HbA1c} \%$. Higher SFI was also significantly associated with cholesterol levels, whereupon a higher SFI was associated with lower HDL and TC levels.

\section{DISCUSSION:}

This is the first study to investigate sleep quantity and quality, incorporating objective measures of sleep to determine the relationship between poor sleep and cardio-metabolic risk factors in Indigenous Australian adults. We identified that a large proportion of Indigenous Australians experience sleep problems at night and that lifestyle behaviours such as smoking and metabolic disorders such as diabetes negatively impact sleep. Importantly, poor sleep quantity and quality were independently associated with elevated BP, $\mathrm{HbA1c} \%$ and cholesterol levels, indicating that improvement of sleep health may be a potential target, alongside other traditional risk factors, for the improvement of cardio-metabolic health.

Overall, we identified that a high proportion of Indigenous Australian adults did not obtain the recommended amount of sleep (between 7-9 hours) with over one-third reporting $<7$ hours/night and objective measures confirming these findings. Sleep disruption was also high amongst Indigenous Australians with almost half of the population reporting poor sleep quality (sleep quality score $<2$ ) and actigraphic data showing fragmented sleep throughout the night, as reflected by a high number of awakenings (average of 6/night) and WASO (Table1). Comparison of sleep duration from this study to current population norms is difficult as studies have used different criteria to define short/normal/long sleep durations. The most recent report by the Australian Sleep Health Foundation found that $12 \%$ of Australian adults experience very short sleep duration of $<5.5$ hours sleep/night (Adams et al., 2017) and another study of 14,900 adults reported that $20 \%$ experience short sleep duration $<6$ hours/night (Lallukka et al., 2018). For comparative purposes, analysis of the $\mathrm{BIRCH}$ cohort revealed that $16 \%$ reported $<5.5$ hours of sleep and $20 \%$ reported $<6$ hours/sleep night. A large degree of sleep disruption was experienced by participants, emphasised by a large proportion having 3 or more awakenings 
(actigraphy measured) and WASO of $>30 \mathrm{~min}$. Both of these symptoms are predictors of clinical insomnia (Bathgate et al., 2017; Natale et al., 2009), indicating that Indigenous Australians may experience fragmented sleep at a level commensurate with clinically significant sleep disorders.

Importantly, poor sleep quantity/and or quality in this population had a significant impact on daytime behaviours, with almost one-third of individuals scoring an elevated ESS $(\geq 10)$, a proportion almost 1.5 times the population norms in Australian adults previously estimated as $19.1 \%$ (Economics, 2017). This is of concern as an elevated ESS $(\geq 10)$ is generally indicative of a clinically significant sleep problem (Johns, 1992). In this population, participants reported a high proportion of apnoea (20\%) and snoring at night (58\%), a prevalence much higher than populations norms estimated in Australian adults (11.9\% and 20.2\% for snoring and apnoea at night, respectively) (Adams et al., 2017). However, these self-report data need to be interpreted with caution and gold-standard assessment of sleep disordered breathing (ie, polysomnography recordings) is required to validate these findings. Nonetheless, these data are in agreement with studies of Indigenous populations from the United States and New Zealand, who have a higher prevalence of OSA compared to non-Indigenous people (Woods, Usher, \& Maguire, 2015). Furthermore, Indigenous Australians are 1.8 times more likely to be diagnosed with OSA if they undergo a diagnostic sleep study, access diagnostic sleep studies at a lower rate and have higher severity of disease compared to non-Indigenous Australians (Heraganahally et al., 2019; Woods et al., 2015). Taken together, these findings highlight the importance of improving diagnosis and access to care for sleep problems including sleep disordered breathing in Indigenous Australians. Given that OSA is a major risk factor for both hypertension and CVD (Floras, 2018), better diagnosis and treatment of these sleep disorders may represent a fundamental target for improvement of cardiovascular health in this population.

In this study we also assessed potential environmental, lifestyle, and biological determinants of poor sleep. Region of residence, rather than sleeping environment (i.e no. people in room/bed and type of bedding) was a significant predictor of sleep problems, with individuals residing in Northern Territory having more sleep disruption compared to Queensland. Region as a predictor of sleep measures, may reflect community/social related determinants of sleep, such as housing, employment, education and neighbourhood factors not assessed in this study. Accordingly, these results highlight the need to assess both environmental and social determinants of sleep in this population, particularly as recent studies indicate that adverse neighbourhood factors in disadvantaged areas can negatively impact sleep at night (Simonelli 
et al., 2017). A number of lifestyle behaviours may also reflect key modifiable targets for the improvement of sleep health, with smoking associated with short sleep duration and alcohol intake with higher levels of daytime sleepiness (ESS score). These associations possibly reflect the known effect of tobacco and alcohol use on sleep architecture, via a reduction in sleep efficiency (Cohen, Colodner, Masalha, \& Haimov, 2019) and sleep state distribution, respectively (Colrain, Nicholas, \& Baker, 2014). Furthermore, modifiable biological factors also contributed to poor sleep at night. Self-report apnoea at night (reflecting individuals at risk of OSA), diabetes and physical discomfort throughout the night (main cause being neck or back pain) were associated with daytime deficits and increased sleep disruption. These results indicate that better diagnosis and management of pathological conditions such as OSA, diabetes and muscular or joint pain may also be vital for the improvement of sleep quality.

The final aim of this study was to determine the associations between sleep and cardiometabolic health. In Indigenous Australian adults, we identified that poor sleep quantity and quality was associated with higher cardio-metabolic risk. Short sleep duration ( $<6$ hours) was associated with higher BP and higher amounts of sleep disruption was associated with higher HbAlc and lower HDL levels. In this study we used the same definition of short sleep duration $<6$ hours/night for both subjective and objective methods. However, self-report sleep duration is not the same as actigraphy measured sleep duration and therefore interpreting these data must be kept in the context of the method of sleep assessment. A sub-analysis of the data did reveal that self-report sleep duration was significantly correlated with actigraphy TST $(\mathrm{R}=0.68, \mathrm{p}<0.05)$. Nonetheless, these findings are in agreement with epidemiological data showing that shorter sleep duration at night is independently associated with higher BP, hypertension (Knutson et al., 2009), CVD and mortality (Tobaldini et al., 2019). Furthermore sleep fragmentation has previously been linked to higher risk of type 2 diabetes (Cappuccio, D'Elia, Strazzullo, \& Miller, 2010) and dyslipidaemia (Qian et al., 2016).

The mechanisms linking short sleep duration and fragmented sleep with cardiometabolic risk is thought to involve sympathetic overactivity, altered adrenocortical activity and inflammatory processes (Tobaldini et al., 2017; Zhang et al., 2011). Experimental sleep deprivation studies show that short sleep duration can increase sympathetic activity and BP and significantly blunt the normal BP dipping profile (Yang, Haack, Gautam, Meier-Ewert, \& Mullington, 2017; Zhang et al., 2011). Sleep fragmentation may also alter lipid metabolism, as arousal responses during sleep activate the hypothalamic-pituitary-adrenal axis which plays a role in lipolysis and affects blood lipids (Qian et al., 2016). Furthermore sleep fragmentation is also known to 
cause systemic inflammation (van Leeuwen et al., 2009), which is known to decrease HDL levels (Feingold \& Grunfeld, 2016). In regards to blood glucose levels, the combination of increased sympathetic tone, adrenocortical activity and insulin resistance may potentially mediate the adverse effects of sleep disruption on glucose metabolism (Spiegel, Tasali, Leproult, \& Van Cauter, 2009). A high proportion (27\%) of participants in this study had diagnosed type 2 diabetes and sleep disruption worsens glycaemic control in diabetes (Chasens, Korytkowski, Sereika, \& Burke, 2013). However, the association identified in this study was independent of self-report diabetes status, suggesting that sleep disturbance per se may alter glucose regulation in this population. Diabetes may also disrupt sleep through common complications such as pain from peripheral neuropathy or nocturia from poor glycaemic control (Ogilvie \& Patel, 2018).

It is important to note some of the limitations of this study. Firstly, this study was an observational study and did not include a non-Indigenous comparison group and therefore direct comparisons within the same regions could not be made. While we sampled populations from three different sites, the majority of the population studied resided in Palm Island (81\%) and may not be representative of Indigenous adults across Australia. These data are representative of Indigenous Australians living in regional and remote Aboriginal communities, which reflect $65 \%$ of the Aboriginal population. In general, Indigenous Australians living in a regional or remote areas share systemic and social disadvantage including lack of health services, low levels of education and school attendance, high unemployment rates, decaying infrastructure, poor housing and high crime rates. Many of these issues are also prominent in Indigenous Australians in living in urban areas, however these data cannot be assumed to be representative of Indigenous Australians in urban communities. Future studies will need to include Indigenous Australian adults from a number of representative communities including both remote and urban settings. Of note, his study only reports associations between sleep and cardiometabolic risk and therefore cause and effect cannot be determined and due to the study design, objective sleep measures were assessed prospectively of cardiometabolic risk measures and therefore prior sleep effects were not controlled for. Importantly, while we did perform face-face interview in 245 Indigenous Australians, we only obtained 46 actigraphic measures. To our knowledge this is the only objective data collected via actigraphy on sleep to be collected in Indigenous Australian adults within community, though we do acknowledge that the gold standard for objective sleep assessment is PSG. With the absence of PSG measures, we were also unable to accurately assess incidence of sleep disordered breathing. Finally, to 
our knowledge there is no validated tool to assess daytime sleepiness in Indigenous Australians. In this study we employed the ESS, however given that some of the questions were not always applicable in disadvantaged populations (e.g questions about driving cars) findings should be interpreted with caution.

Despite these limitations, sleep health may represent a potential modifiable target for prevention of CVD in Indigenous populations. Given the association between poor sleep and cardio-metabolic health. Targeted, brief, sleep health programs can improve sleep problems in adults and reduce biomarkers of diabetes and CVD risk (Carroll et al., 2015). However, whether these same sleep health programs and their benefits can be translated to Indigenous populations is unknown. In order to develop such programs, a better understanding to potential barriers/determinants of sleep in Indigenous populations is required. In this study, we identified both behavioural (e.g smoking) and biological (e.g diabetes and sleep disordered breathing) determinants of poor sleep, potentially indicating that some simple sleep health education, particularly surrounding sleep habits and consequences of sleep problems, may be beneficial for improvement of sleep. However, when considering such programs, the complex combination and the ongoing impact of historical, institutional, socio-cultural, economic, environmental and lifestyle related factors as well as access to healthcare must be remembered in Indigenous people (Stoner et al., 2017). Of utmost importance, if any sleep health education program is to be developed and implemented in Indigenous populations, it is imperative that these programs are developed in consultation with, informed by and identified by the Indigenous community.

In conclusion, similar to other countries which have arisen from European colonization, a high proportion of Indigenous Australians experience poor sleep quantity and quality at night. Factors such as smoking, alcohol, sleeping environment and sleep disordered breathing may be contributors to this poor sleep. Importantly, poor sleep at night in Indigenous Australians negatively impacts BP, HbA1c and cholesterol levels. Better sleep at night may improve cardio-metabolic risk, however future studies are required to determine whether this approach is feasible and effective. Taken together, this study suggests that engagement with community to improve sleep health and access to sleep related health care may be vital to enhance health and well-being in Indigenous Australians, with particular gain to reduce inequity in CVD. 


\section{ACKNOWLEDGEMENTS:}

This project is supported by the Australian Catholic University, the NHMRC Centre for Research Excellence to Reduce Inequality in Heart Disease and the Victorian Government's Operational Infrastructure Support Program. SY is support by the Gender Equity Award, Baker Heart and Diabetes Institute. GM is supported by an NHMRC Practitioner Fellowship. MJC is supported by a Future Leader Fellowship (Award Reference 100802) from the National Heart Foundation of Australia. We also acknowledge engagement and support from health services and community councils involved in the BIRCH study (including Aboriginal communitycontrolled health services and councils; Tangentyere Town Camp Council, Central Australian Aboriginal Congress in the Northern Territory, Yarrabah and Palm Island Councils in North Queensland and Wurli-wurlinjang Health Service).

\section{DISCLOSURE STATEMENT}

Financial Disclosure: none.

Non-financial Disclosure: none

\section{AUTHOR CONTRIBUTIONS}

SY contributed to the study design, co-ordinated and collected data, carried out data analysis and interpretation, drafted the initial manuscript and reviewed and revised the manuscript. MJC and GPM conceptualized and designed the study, obtained funding and reviewed and revised the manuscript.

\section{REFERENCES:}

Adams, R. J., Appleton, S. L., Taylor, A. W., Gill, T. K., Lang, C., McEvoy, R. D., \& Antic, N. A. (2017). Sleep health of Australian adults in 2016: results of the 2016 Sleep Health Foundation national survey. Sleep Health, 3(1), 35-42. doi:10.1016/j.sleh.2016.11.005 
AIHW. (2015). The health and welfare of Australia's Aboriginal and Torres Strait Islander peoples 2015. In AIHW (Ed.). Canberra.

Ancoli-Israel, S., Cole, R., Alessi, C., Chambers, M., Moorcroft, W., \& Pollak, C. P. (2003). The role of actigraphy in the study of sleep and circadian rhythms. Sleep, 26(3), 342-392.

Ancoli-Israel, S., Martin, J. L., Blackwell, T., Buenaver, L., Liu, L., Meltzer, L. J., . . . Taylor, D. J. (2015). The SBSM Guide to Actigraphy Monitoring: Clinical and Research Applications. Behav Sleep Med, 13 Suppl 1, S4-S38. doi:10.1080/15402002.2015.1046356

Barreira, T. V., Redmond, J. G., Brutsaert, T. D., Schuna, J. M., Jr., Mire, E. F., Katzmarzyk, P. T., \& Tudor-Locke, C. (2018). Can an automated sleep detection algorithm for waist-worn accelerometry replace sleep logs? Appl Physiol Nutr Metab, 43(10), 1027-1032. doi:10.1139/apnm-2017-0860

Bathgate, C. J., Edinger, J. D., \& Krystal, A. D. (2017). Insomnia Patients With Objective Short Sleep Duration Have a Blunted Response to Cognitive Behavioral Therapy for Insomnia. Sleep, 40(1). doi:10.1093/sleep/zsw012

Cappuccio, F. P., D'Elia, L., Strazzullo, P., \& Miller, M. A. (2010). Quantity and quality of sleep and incidence of type 2 diabetes: a systematic review and meta-analysis. Diabetes Care, 33(2), 414420. doi:10.2337/dc09-1124

Carroll, J. E., Seeman, T. E., Olmstead, R., Melendez, G., Sadakane, R., Bootzin, R., . . Irwin, M. R. (2015). Improved sleep quality in older adults with insomnia reduces biomarkers of disease risk: pilot results from a randomized controlled comparative efficacy trial. Psychoneuroendocrinology, 55, 184-192. doi:10.1016/j.psyneuen.2015.02.010

Chasens, E. R., Korytkowski, M., Sereika, S. M., \& Burke, L. E. (2013). Effect of poor sleep quality and excessive daytime sleepiness on factors associated with diabetes self-management. Diabetes Educ, 39(1), 74-82. doi:10.1177/0145721712467683

Cohen, A., Colodner, R., Masalha, R., \& Haimov, I. (2019). The Relationship Between Tobacco Smoking, Cortisol Secretion, and Sleep Continuity. Subst Use Misuse, 54(10), 1705-1714. doi: $10.1080 / 10826084.2019 .1608250$

Colrain, I. M., Nicholas, C. L., \& Baker, F. C. (2014). Alcohol and the sleeping brain. Handb Clin Neurol, 125, 415-431. doi:10.1016/B978-0-444-62619-6.00024-0

Economics, D. A. (2017). Asleep on the job: Costs of Inadequate Sleep in Australia Retrieved from www.sleephealthfoundation.org.au:

Feingold, K. R., \& Grunfeld, C. (2016). Effect of inflammation on HDL structure and function. Curr Opin Lipidol, 27(5), 521-530. doi:10.1097/MOL.0000000000000333

Floras, J. S. (2018). Sleep Apnea and Cardiovascular Disease: An Enigmatic Risk Factor. Circ Res, 122(12), 1741-1764. doi:10.1161/CIRCRESAHA.118.310783 
Full, K. M., Kerr, J., Grandner, M. A., Malhotra, A., Moran, K., Godoble, S., . . Soler, X. (2018). Validation of a physical activity accelerometer device worn on the hip and wrist against polysomnography. Sleep Health, 4(2), 209-216. doi:10.1016/j.sleh.2017.12.007

Gottlieb, D. J., Redline, S., Nieto, F. J., Baldwin, C. M., Newman, A. B., Resnick, H. E., \& Punjabi, N. M. (2006). Association of usual sleep duration with hypertension: the Sleep Heart Health Study. Sleep, 29(8), 1009-1014. doi:10.1093/sleep/29.8.1009

Gray C, B. A., Thomson N (2012). Review of cardiovascular health among Indigenous Australians. Retrieved from

Gubhaju, L., Banks, E., Macniven, R., Joshy, G., McNamara, B. J., Bauman, A., \& Eades, S. J. (2016). Factors relating to participation in follow-up to the 45 and up study in Aboriginal and nonAboriginal individuals. BMC Med Res Methodol, 16, 53. doi:10.1186/s12874-016-0155-x

Heraganahally, S. S., Kruavit, A., Oguoma, V. M., Gokula, C., Mehra, S., Judge, D., \& Sajkov, D. (2019). Sleep apnoea among Australian Aboriginal and Non- Aboriginal patients in the Northern Territory of Australia- a comparative study. Sleep. doi:10.1093/sleep/zsz248

Johns, M. W. (1992). Reliability and factor analysis of the Epworth Sleepiness Scale. Sleep, 15(4), 376381. doi:10.1093/sleep/15.4.376

Killick, R., Banks, S., \& Liu, P. Y. (2012). Implications of sleep restriction and recovery on metabolic outcomes. J Clin Endocrinol Metab, 97(11), 3876-3890. doi:10.1210/jc.2012-1845

Knutson, K. L., Van Cauter, E., Rathouz, P. J., Yan, L. L., Hulley, S. B., Liu, K., \& Lauderdale, D. S. (2009). Association between sleep and blood pressure in midlife: the CARDIA sleep study. Arch Intern Med, 169(11), 1055-1061. doi:10.1001/archinternmed.2009.119

Lallukka, T., Sivertsen, B., Kronholm, E., Bin, Y. S., Overland, S., \& Glozier, N. (2018). Association of sleep duration and sleep quality with the physical, social, and emotional functioning among Australian adults. Sleep Health, 4(2), 194-200. doi:10.1016/j.sleh.2017.11.006

Macniven, R., Richards, J., Gubhaju, L., Joshy, G., Bauman, A., Banks, E., \& Eades, S. (2016). Physical activity, healthy lifestyle behaviors, neighborhood environment characteristics and social support among Australian Aboriginal and non-Aboriginal adults. Prev Med Rep, 3, 203-210. doi:10.1016/j.pmedr.2016.01.006

Natale, V., Plazzi, G., \& Martoni, M. (2009). Actigraphy in the assessment of insomnia: a quantitative approach. Sleep, 32(6), 767-771. doi:10.1093/sleep/32.6.767

Ogilvie, R. P., \& Patel, S. R. (2018). The Epidemiology of Sleep and Diabetes. Curr Diab Rep, 18(10), 82. doi:10.1007/s11892-018-1055-8

Ohayon, M. M., Krystal, A., Roehrs, T. A., Roth, T., \& Vitiello, M. V. (2010). Using difficulty resuming sleep to define nocturnal awakenings. Sleep Med, 11(3), 236-241. doi:10.1016/j.sleep.2009.11.004 
Paine, S. J., Harris, R., Cormack, D., \& Stanley, J. (2017). Self-reported sleep complaints are associated with adverse health outcomes: cross-sectional analysis of the 2002/03 New Zealand Health Survey. Ethn Health, 1-13. doi:10.1080/13557858.2017.1315368

Qian, Y., Yi, H., Zou, J., Meng, L., Tang, X., Zhu, H., . . Y Yin, S. (2016). Independent Association between Sleep Fragmentation and Dyslipidemia in Patients with Obstructive Sleep Apnea. Sci Rep, 6, 26089. doi:10.1038/srep26089

Redline, S., \& Tishler, P. V. (2000). The genetics of sleep apnea. Sleep Med Rev, 4(6), 583-602. doi: $10.1053 /$ smrv.2000.0120

Remond, M. G. W., Stewart, S., Carrington, M. J., Marwick, T. H., Kingwell, B. A., Meikle, P., . . . Maguire, G. P. (2017). Better Indigenous Risk stratification for Cardiac Health study (BIRCH) protocol: rationale and design of a cross-sectional and prospective cohort study to identify novel cardiovascular risk indicators in Aboriginal Australian and Torres Strait Islander adults. $B M C$ Cardiovase Disord, 17(1), 228. doi:10.1186/s12872-017-0662-7

Sabanayagam, C., Shankar, A., Buchwald, D., \& Goins, R. T. (2011). Insomnia symptoms and cardiovascular disease among older American Indians: the Native Elder Care Study. J Environ Public Health, 2011, 964617. doi:10.1155/2011/964617

Simonelli, G., Dudley, K. A., Weng, J., Gallo, L. C., Perreira, K., Shah, N. A., . . Patel, S. R. (2017). Neighborhood Factors as Predictors of Poor Sleep in the Sueno Ancillary Study of the Hispanic Community Health Study/Study of Latinos. Sleep, 40(1). doi:10.1093/sleep/zsw025

Spiegel, K., Tasali, E., Leproult, R., \& Van Cauter, E. (2009). Effects of poor and short sleep on glucose metabolism and obesity risk. Nat Rev Endocrinol, 5(5), 253-261. doi:10.1038/nrendo.2009.23

St-Onge, M. P., Grandner, M. A., Brown, D., Conroy, M. B., Jean-Louis, G., Coons, M., . . Stroke, C. (2016). Sleep Duration and Quality: Impact on Lifestyle Behaviors and Cardiometabolic Health: A Scientific Statement From the American Heart Association. Circulation, 134(18), e367-e386. doi:10.1161/CIR.0000000000000444

Stoner, L., Matheson, A. G., Perry, L. G., Williams, M. A., McManus, A., Holdaway, M., . . Maiorana, A. (2017). Principles and strategies for improving the prevention of cardio-metabolic diseases in indigenous populations: An international Delphi study. Prev Med, 96, 106-112. doi:10.1016/j.ypmed.2016.12.050

Tobaldini, E., Costantino, G., Solbiati, M., Cogliati, C., Kara, T., Nobili, L., \& Montano, N. (2017). Sleep, sleep deprivation, autonomic nervous system and cardiovascular diseases. Neurosci Biobehav Rev, 74(Pt B), 321-329. doi:10.1016/j.neubiorev.2016.07.004

Tobaldini, E., Fiorelli, E. M., Solbiati, M., Costantino, G., Nobili, L., \& Montano, N. (2019). Short sleep duration and cardiometabolic risk: from pathophysiology to clinical evidence. Nat Rev Cardiol, 16(4), 213-224. doi:10.1038/s41569-018-0109-6

van Leeuwen, W. M., Lehto, M., Karisola, P., Lindholm, H., Luukkonen, R., Sallinen, M., .. . Alenius, H. (2009). Sleep restriction increases the risk of developing cardiovascular diseases by 
augmenting proinflammatory responses through IL-17 and CRP. PLoS One, 4(2), e4589. doi:10.1371/journal.pone.0004589

WHO. (2007). Health of indigenous peoples. Retrieved from http://www.who.int/mediacentre/factsheets/fs326/en/\#.WhtNJmG2MG0.email

Woods, C. E., Usher, K., \& Maguire, G. P. (2015). Obstructive sleep apnoea in adult indigenous populations in high-income countries: an integrative review. Sleep Breath, 19(1), 45-53. doi: 10.1007/s11325-014-1032-7

Yang, H., Haack, M., Gautam, S., Meier-Ewert, H. K., \& Mullington, J. M. (2017). Repetitive exposure to shortened sleep leads to blunted sleep-associated blood pressure dipping. J Hypertens, 35(6), 1187-1194. doi:10.1097/HJH.0000000000001284

Zhang, J., Ma, R. C., Kong, A. P., So, W. Y., Li, A. M., Lam, S. P., . . Wing, Y. K. (2011). Relationship of sleep quantity and quality with 24-hour urinary catecholamines and salivary awakening cortisol in healthy middle-aged adults. Sleep, 34(2), 225-233.

\section{FIGURE LEGENDS:}

Figure 1: Location of the Indigenous remote communities (Katherine, Alice Springs, and Palm Island) within Northern Territory and North Queensland that were sample as part of the BIRCH study.

Figure 2: Descriptive data on sleeping environment and potential barriers to sleep in Indigenous Australian adults including a) no. of people sharing a bed b) no. people sharing the same room c) Type of bedding d) Physical complaints which disrupt sleep e) no. drinks of tea f) no. drinks coffee/day g) no. drinks of cola/day and h) no. standard alcoholic drinks/day.

Table 1: Cardiometabolic risk and sleep (subjective and objective) measures in Indigenous Australians according to gender and study site.

\begin{tabular}{lccccc}
\hline & MALE & FEMALE & $\begin{array}{c}\text { NORTHERN } \\
\text { TERRITORY }\end{array}$ & QUEENSLAND & TOTAL \\
\hline Cardio-metabolic risk measures & & & & & \\
\hline N & $105(43 \%)$ & $140(57 \%)$ & $46(19 \%)$ & $199(81 \%)$ & 245 \\
Age (years) & $47 \pm 14$ & $44 \pm 14$ & $47 \pm 14$ & $44 \pm 14$ & $45 \pm 13$ \\
Waist circumference (cm) & $99 \pm 15$ & $101 \pm 16$ & $102 \pm 17$ & $100 \pm 16$ & $100 \pm 16$ \\
Neck circumference (cm) & $41 \pm 5$ & $38 \pm 4^{\dagger}$ & $40 \pm 4$ & $39 \pm 5$ & $39 \pm 5$ \\
BMI (kg/m ${ }^{2}$ ) & $27 \pm 6$ & $29 \pm 7^{\dagger}$ & $28 \pm 7$ & $28 \pm 6$ & $28 \pm 6$ \\
Alcohol (standard drinks/day) & $1.32 \pm 3.24$ & $1.09 \pm 2.8$ & $3 \pm 5$ & $0 \pm 1 *$ & $1 \pm 2$ \\
Diabetes & $27(26 \%)$ & $40(29 \%)$ & $18(40 \%)$ & $49(25 \%)$ & $67(27 \%)$ \\
Smoking & $68(65 \%)$ & $91(66 \%)$ & $23(50 \%)$ & $136(68 \%)^{*}$ & $159(65 \%)$ \\
SBP (mmHg) & $127 \pm 21$ & $119 \pm 21^{\dagger}$ & $124 \pm 21$ & $122 \pm 21$ & $123 \pm 21$
\end{tabular}




\begin{tabular}{|c|c|c|c|c|c|}
\hline DBP (mmHg) & $80 \pm 13$ & $78 \pm 11$ & $80 \pm 12$ & $79 \pm 11$ & $79 \pm 12$ \\
\hline $\mathrm{HbAlc}(\%)$ & $6.37 \pm 1.43$ & $6.43 \pm 1.62$ & $6.62 \pm 1.55$ & $6.34 \pm 1.53$ & $6.39 \pm 1.53$ \\
\hline Total cholesterol (mmol/l) & $4.36 \pm 1.03$ & $4.16 \pm 0.88$ & $4.07 \pm 0.9$ & $4.28 \pm 0.96$ & $4.24 \pm 0.95$ \\
\hline LDL cholesterol $(\mathrm{mmol} / \mathrm{l})$ & $2.42 \pm 0.84$ & $2.23 \pm 0.76$ & $2.04 \pm 0.74$ & $2.37 \pm 0.8^{*}$ & $2.31 \pm 0.79$ \\
\hline HDL cholesterol (mmol/l) & $1.14 \pm 0.27$ & $1.12 \pm 0.25$ & $1.23 \pm 0.31$ & $1.11 \pm 0.24 *$ & $1.13 \pm 0.26$ \\
\hline Triglycerides $(\mathrm{mmol} / \mathrm{l})$ & $1.89 \pm 1.39$ & $1.8 \pm 1.05$ & $1.91 \pm 1.34$ & $1.82 \pm 1.18$ & $1.84 \pm 1.21$ \\
\hline \multicolumn{6}{|l|}{ Subjective sleep measures } \\
\hline $\mathrm{N}$ & $105(43 \%)$ & $140(57 \%)$ & $46(19 \%)$ & $199(81 \%)$ & 245 \\
\hline Sleep Quality Score & $3 \pm 1$ & $3 \pm 1$ & $3 \pm 1$ & $3 \pm 1$ & $3 \pm 1$ \\
\hline$\leq 2$ & $51(49 \%)$ & $86(65 \%)^{\dagger}$ & $25(63 \%)$ & $112(57 \%)$ & $137(58 \%)$ \\
\hline Snorers & $65(65 \%)$ & $69(53 \%)$ & $25(62 \%)$ & $109(57 \%)$ & $134(20 \%)$ \\
\hline Apnoea at night & $19(19 \%)$ & $27(21 \%)$ & $9(22 \%)$ & $37(19 \%)$ & $46(58 \%)$ \\
\hline Nap duration (min) & $105 \pm 84$ & $98 \pm 61$ & $92 \pm 39$ & $103 \pm 77$ & $102 \pm 73$ \\
\hline$>30 \min$ & $53(84 \%)$ & $55(82 \%)$ & $17(94 \%)$ & $91(81 \%)$ & $108(83 \%)$ \\
\hline ESS score & $7 \pm 4$ & $7 \pm 4$ & $9 \pm 5$ & $6 \pm 4^{*}$ & $7 \pm 5$ \\
\hline $\mathrm{ESS} \geq 10$ & $30(29 \%)$ & $34(26 \%)$ & $20(50 \%)$ & $44(22 \%)^{*}$ & $64(27 \%)$ \\
\hline Sleep Onset Latency (min) & $39 \pm 50$ & $39 \pm 48$ & $38 \pm 36$ & $39 \pm 51$ & $39 \pm 49$ \\
\hline$\geq 30 \mathrm{~min}$ & $34(33 \%)$ & $39(30 \%)$ & $13(32 \%)$ & $60(31 \%)$ & $73(30 \%)$ \\
\hline No. Awakenings & $1 \pm 1$ & $2 \pm 2$ & $2 \pm 1$ & $1 \pm 1$ & $2 \pm 2$ \\
\hline$\geq 3$ & $14(14 \%)$ & $37(28 \%)^{\dagger}$ & $14(35 \%)$ & $37(19 \%)^{*}$ & $51(22 \%)$ \\
\hline Morning tiredness/fatigue Score & $2 \pm 0$ & $2 \pm 1$ & $2 \pm 1$ & $2 \pm 1$ & $2 \pm 1$ \\
\hline$\leq 2$ & $47(45 \%)$ & $71(54 \%)$ & $20(50 \%)$ & $98(50 \%)$ & $118(50 \%)$ \\
\hline **Total Sleep Time (TST) (hrs) & $7.3 \pm 2.6$ & $7.7 \pm 2.3$ & $7.21 \pm 2.1$ & $7.65 \pm 2.5$ & $7.5 \pm 2$ \\
\hline$<6$ hours & $12(24 \%)$ & $13(52 \%)$ & $5(13 \%)$ & $20(23 \%)$ & $25(20 \%)$ \\
\hline$<7$ hours & $21(42 \%)$ & $23(30 \%)$ & $15(38 \%)$ & $29(34 \%)$ & $44(35 \%)$ \\
\hline $7-9$ hours & $16(32 \%)$ & $29(38 \%)$ & $15(38 \%)$ & $30(35 \%)$ & $45(36 \%)$ \\
\hline$>9$ hours & $13(26 \%)$ & $24(32 \%)$ & $10(25 \%)$ & $27(31 \%)$ & $37(29 \%)$ \\
\hline \multicolumn{6}{|l|}{ Objective sleep measures } \\
\hline $\mathrm{N}$ & $21(46 \%)$ & $25(54 \%)$ & $20(43 \%)$ & $26(57 \%)$ & 46 \\
\hline Total Sleep Time (TST) (hrs) & $7.8 \pm 1.8$ & $7.3 \pm 1.5$ & $7.2 \pm 1.5$ & $7.8 \pm 1.6$ & $7.5 \pm 2$ \\
\hline$<6$ hours & $2(10 \%)$ & $5(20 \%)$ & $5(25 \%)$ & $2(8 \%)$ & $7(15 \%)$ \\
\hline$<7$ hours & $8(38 \%)$ & $10(40 \%)$ & $9(45 \%)$ & $9(35 \%)$ & $18(39 \%)$ \\
\hline $7-9$ hours & $8(38 \%)$ & $12(48 \%)$ & $9(45 \%)$ & $11(42 \%)$ & $20(43 \%)$ \\
\hline$>9$ hours & $5(24 \%)$ & $3(12 \%)$ & $2(10 \%)$ & $6(23 \%)$ & $8(17 \%)$ \\
\hline Wake After Sleep Onset (WASO) & $19 \pm 14$ & $29 \pm 42$ & $28 \pm 45$ & $21 \pm 16$ & $24 \pm 33$ \\
\hline$\geq 30 \mathrm{~min}$ & $5(24 \%)$ & $5(20 \%)$ & $3(15 \%)$ & $7(27 \%)$ & $10(22 \%)$ \\
\hline Number of Awakenings & $6 \pm 4$ & $6 \pm 4$ & $5 \pm 4$ & $6 \pm 4$ & $6 \pm 4$ \\
\hline$\geq 3$ & $15(71 \%)$ & $19(76 \%)$ & $16(80 \%)$ & $18(69 \%)$ & $34(74 \%)$ \\
\hline Sleep Fragmentation Index & $29 \pm 17$ & $22 \pm 12$ & $22 \pm 12$ & $27 \pm 16$ & $25 \pm 15$ \\
\hline$\geq 30$ & $9(43 \%)$ & $7(28 \%)$ & $5(25 \%)$ & $11(42 \%)$ & $16(35 \%)$ \\
\hline
\end{tabular}

*P $<0.05$ Northern Territory Vs Queensland

$\dagger \mathrm{p}<0.05$ Male vs female

** $\mathrm{n}=126$, Subjective Total Sleep Time (hrs)

Table 2: Lifestyle, environmental and biological determinants of sleep

\begin{tabular}{lrr}
\hline \multicolumn{2}{c}{ Lifestyle environmental and biological determinants of sleep } \\
\hline \multicolumn{1}{c}{ Subjective sleep measures } \\
\hline P & p value \\
\hline Age (years) & 1.025 & $0.025^{*}$ \\
Female gender & 1.989 & $0.023^{*}$ \\
Physical Complaints & 3.274 & $<0.001^{*}$ \\
Apnoea at night & 0.366 & $0.015^{*}$ \\
\hline
\end{tabular}




\begin{tabular}{|c|c|c|}
\hline \multicolumn{3}{|c|}{$\dagger$ No. self-report awakenings $r^{2}=0.12, p<0.001$} \\
\hline Age (years) & 0.016 & 0.101 \\
\hline Female gender & 0.701 & $0.005^{*}$ \\
\hline Caffeine (serves/day) & 0.072 & $0.030 *$ \\
\hline Diabetes & 0.527 & 0.079 \\
\hline Physical complaints & 0.441 & 0.073 \\
\hline \multicolumn{3}{|l|}{$\dagger \mathrm{ESS} \mathrm{r}^{2}=0.20, \mathrm{p}<0.001$} \\
\hline No. alcoholic drinks/day & 0.338 & $0.001 *$ \\
\hline Apnoea at night & 2.725 & $<0.001 *$ \\
\hline Physical complaints & 1.146 & $0.046^{*}$ \\
\hline North Queensland region & -1.690 & $0.035^{*}$ \\
\hline \multicolumn{3}{|c|}{ Objective sleep measures } \\
\hline \multicolumn{3}{|c|}{$\dagger$ Sleep Duration $(\min ) \mathrm{r}^{2}=\mathbf{0 . 1 3}, \mathrm{p}=\mathbf{0 . 0 2 8}$} \\
\hline Smoking & -64.615 & $0.028 *$ \\
\hline \multicolumn{3}{|c|}{$\dagger$ No. of awakenings $r^{2}=0.18, p=0.008$} \\
\hline Diabetes & -3.166 & $0.008^{*}$ \\
\hline \multicolumn{3}{|c|}{$\dagger$ Sleep Fragmentation Index $\mathbf{r}^{2}=0.22, \quad p=0.012$} \\
\hline Female gender & -10.636 & $0.027 *$ \\
\hline Diabetes & -8.362 & 0.081 \\
\hline
\end{tabular}

$\uparrow$ Models were produced using multiple backward linear regression for continuous dependent variables

$\dagger \dagger$ Models were produced using binary logistic models for dichotomous dependent variables.

The following independent variables were inputted in all models: Age (years), region, diabetes, gender, no. people sleeping in the same room, smoking, no. alcoholic drinks/day, no. caffeinated drinks/day, physical complaints at night and apnea at night.

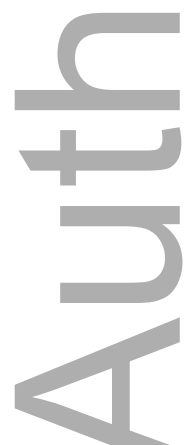

Table 3: Significant predictors of cardio-metabolic risk measures using subjective (questionnaire) and objective (actigraphy based) measures of sleep quality and quantity.

\begin{tabular}{lll}
\hline Dependant variable & B & p value \\
\hline
\end{tabular}




\begin{tabular}{|c|c|c|}
\hline \multicolumn{3}{|l|}{ Systolic Blood Pressure $(\mathrm{mmHg}) \mathrm{r}^{2}=0.22, \mathrm{p}<0.001$} \\
\hline Age (years) & 0.512 & $<0.001 *$ \\
\hline Male gender & 7.234 & $0.026^{*}$ \\
\hline Nap duration $>30$ min & -5.684 & 0.073 \\
\hline \multicolumn{3}{|l|}{ Diastolic Blood Pressure $(\mathrm{mmHg}) \mathrm{r}^{2}=0.16, p<0.001$} \\
\hline Age (years) & 0.209 & $0.003 *$ \\
\hline BMI $\left(\mathrm{kg} / \mathrm{m}^{2}\right)$ & 0.285 & $0.049 *$ \\
\hline Short Sleep duration ( $\leq 6$ hours) & 5.367 & $0.038^{*}$ \\
\hline \multicolumn{3}{|l|}{ HbA1c $(\%) r^{2}=0.56, p<0.001$} \\
\hline BMI $\left(\mathrm{kg} / \mathrm{m}^{2}\right)$ & 0.027 & 0.073 \\
\hline Smoking & 0.418 & 0.050 \\
\hline Diabetes & 2.256 & $<0.001 *$ \\
\hline Long Sleep Duration ( $\geq 9$ hours) & 0.400 & 0.086 \\
\hline \multicolumn{3}{|l|}{ Total Cholesterol $(\mathrm{mmol} / \mathrm{l}) \mathrm{r}^{2}=0.10, \mathrm{p}=0.002$} \\
\hline Age (years) & 0.018 & $0.003 *$ \\
\hline Diabetes & -0.583 & $0.003 *$ \\
\hline \multicolumn{3}{|l|}{ LDL $(\mathrm{mmol} / \mathrm{l}) \mathrm{r}^{2}=0.10, \mathrm{p}=0.002$} \\
\hline Diabetes & -0.417 & $0.005^{*}$ \\
\hline Long Sleep Duration ( $\geq 9$ hours) & -0.328 & 0.050 \\
\hline \multicolumn{3}{|l|}{ HDL $(\mathrm{mmol} / \mathrm{l}) \mathrm{r}^{2}=0.13, \mathrm{p}<0.001$} \\
\hline Age (years) & 0.005 & $0.008^{*}$ \\
\hline Diabetes & -0.213 & $<0.001 *$ \\
\hline \multicolumn{3}{|l|}{ Triglycerides $(\mathrm{mmol} / \mathrm{l}) \mathrm{r}^{2}=0.17, \mathrm{p}<0.001$} \\
\hline Age (years) & 0.019 & $0.001 *$ \\
\hline $\operatorname{BMI}\left(\mathrm{kg} / \mathrm{m}^{2}\right)$ & 0.035 & $0.003 *$ \\
\hline Objective sleep measures ${ }^{\dagger \dagger} n=46$ & & \\
\hline \multicolumn{3}{|l|}{ Systolic Blood Pressure $(\mathrm{mmH}) \mathrm{r}^{2}=0.24, \mathrm{p}=0.003$} \\
\hline Age (years) & 0.579 & $0.003 *$ \\
\hline Short Sleep duration ( $\leq 6$ hours) & 14.300 & $0.048^{*}$ \\
\hline \multicolumn{3}{|l|}{ Diastolic Blood Pressure $(\mathrm{mmHg}) \mathrm{r}^{2}=0.11, p=0.028$} \\
\hline BMI $\left(\mathrm{kg} / \mathrm{m}^{2}\right)$ & 0.515 & $0.028 *$ \\
\hline \multicolumn{3}{|l|}{ HbA1c (\%) $r^{2}=0.67, p<0.001$} \\
\hline Diabetes & 2.343 & $<0.001 *$ \\
\hline No. Awakenings & 0.073 & $0.020^{*}$ \\
\hline
\end{tabular}

Total Cholesterol $(\mathrm{mmol} / \mathrm{l}) \mathrm{r}^{2}=\mathbf{0 . 2 6}, \mathrm{p}=\mathbf{0 . 0 0 5}$

This article is protected by copyright. All rights reserved 
Male gender

$0.809 \quad 0.005^{*}$

Diabetes

$-0.555 \quad 0.052$

Sleep Fragmentation Index

$-0.021 \quad 0.029 *$

\section{LDL $(\mathrm{mmol} / \mathrm{l}) \mathrm{r}^{2}=0.28, \mathrm{p}=0.001$}

Male gender

$0.691 \quad 0.003 *$

Diabetes

$-0.427$

0.065

HDL $(\mathrm{mmol} / \mathrm{l}) \mathrm{r}^{2}=0.11, \mathrm{p}=0.025$

Sleep Fragmentation Index

$-0.006 \quad 0.025^{*}$

Models were produced using backward multiple linear regression. All models were adjusted for age (years), gender (male/female), BMI and smoking status. Models for HbA1c, Total Cholesterol, LDL and HDL were additionally adjusted for diabetic status.

†ndependent variables included in models: self-rated sleep quality, short sleep duration, long sleep duration.

††Independent variables included in models: total sleep time (min), No. of awakenings, sleep fragmentation index.

$* \mathrm{p}<0.05$
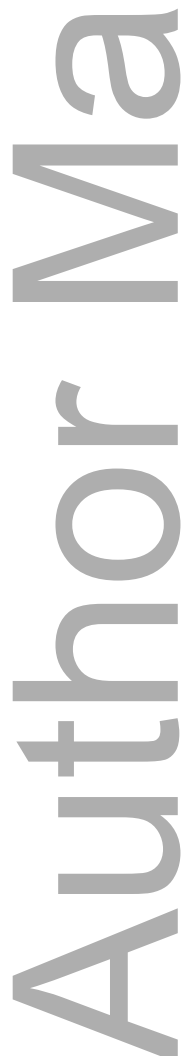

This article is protected by copyright. All rights reserved 
Figure 1:

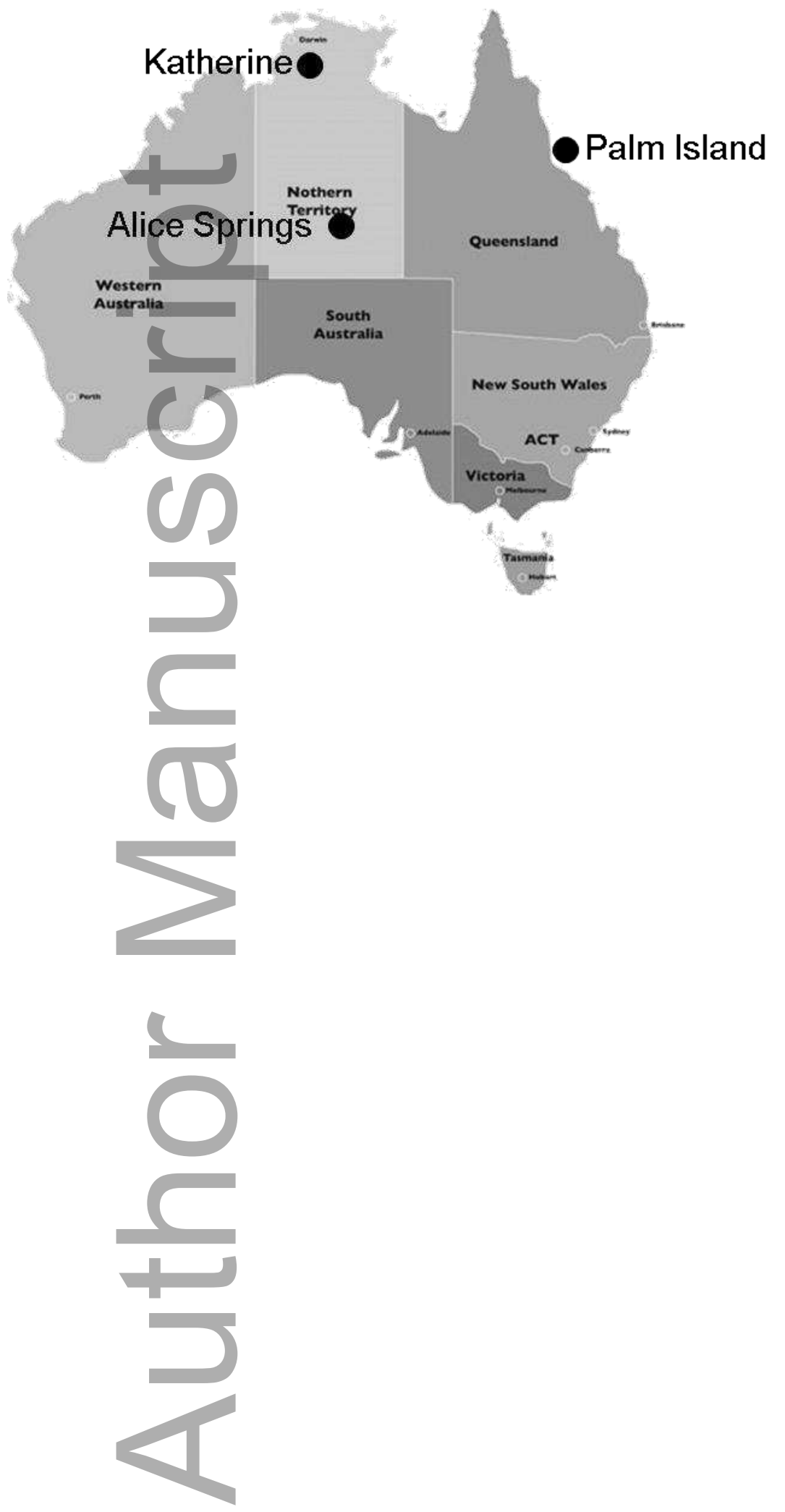

This article is protected by copyright. All rights reserved 
Figure 2:

Bed sharing

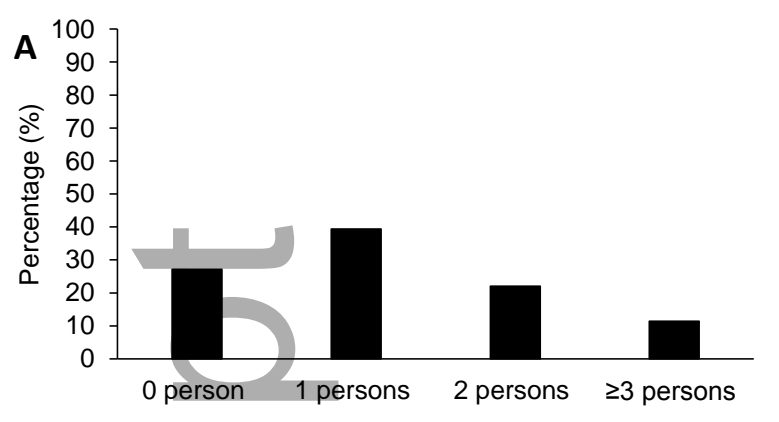

-

Type of Bedding

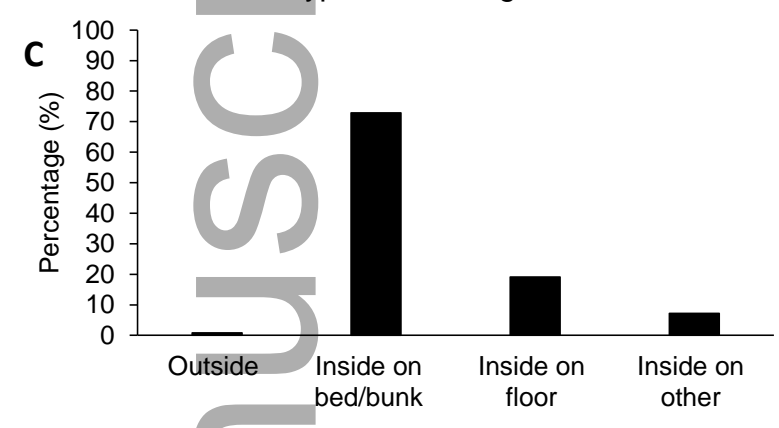

Caffeine/Tea Per Day
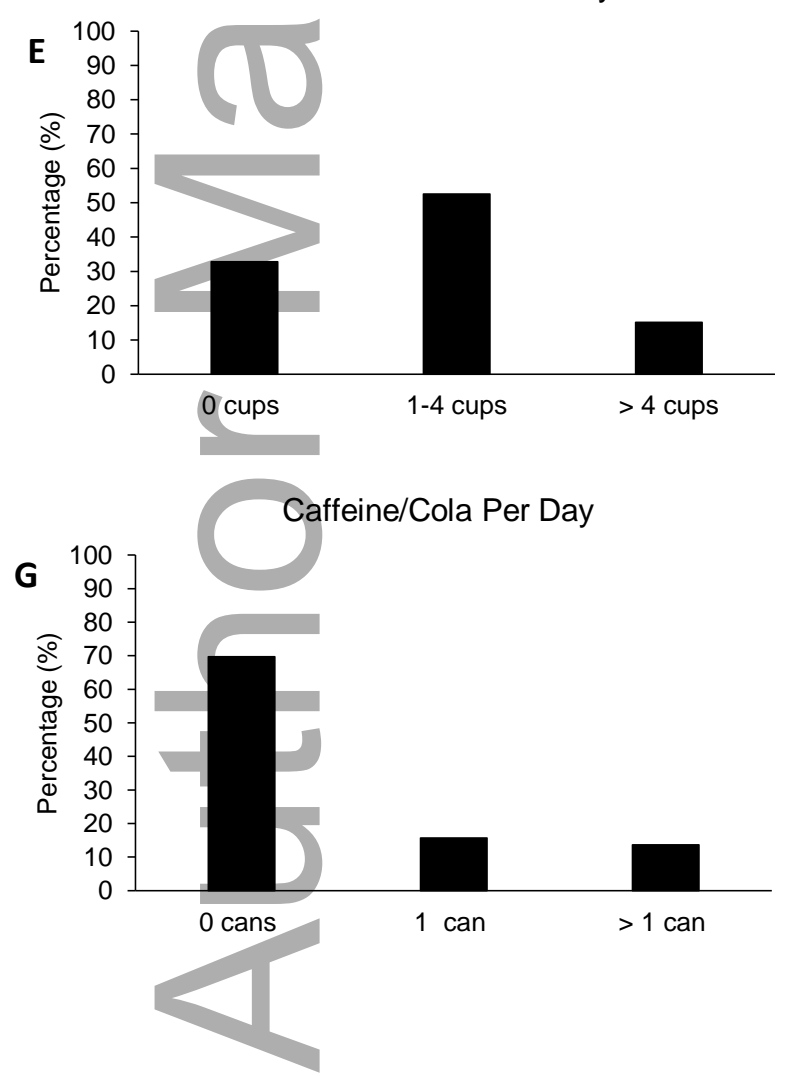

Room sharing

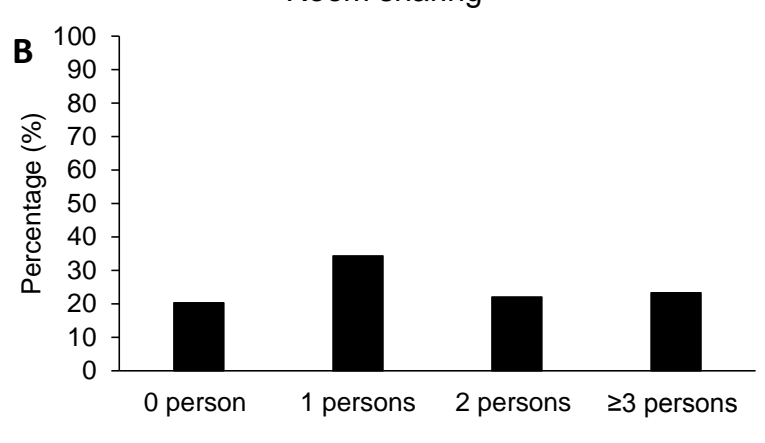

Physical Complaint

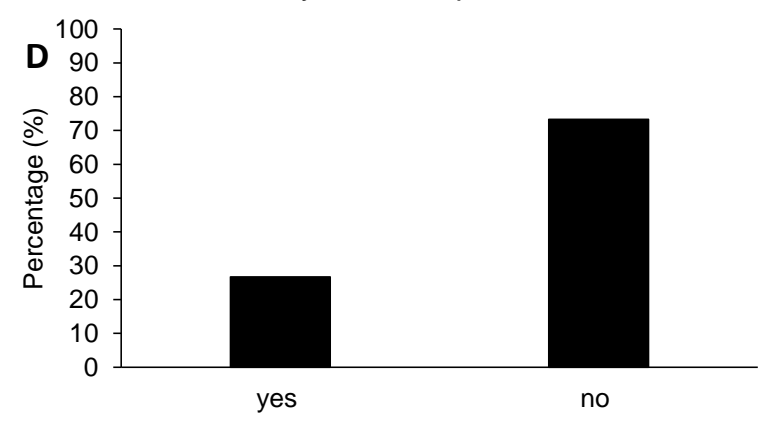

Caffeine/Coffee Per Day

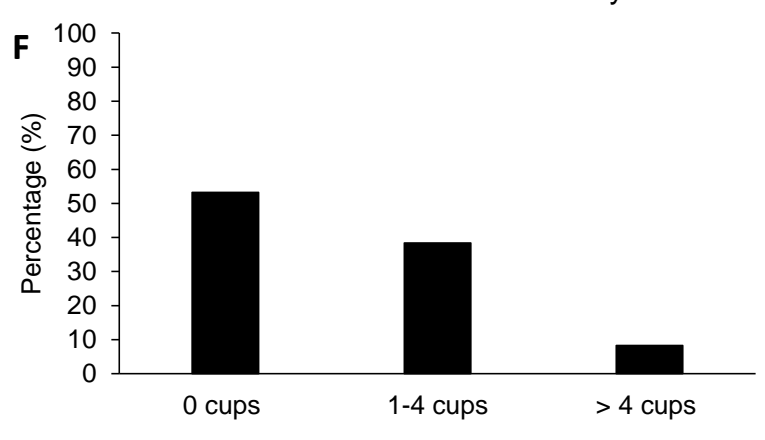

Alcohol Per Day

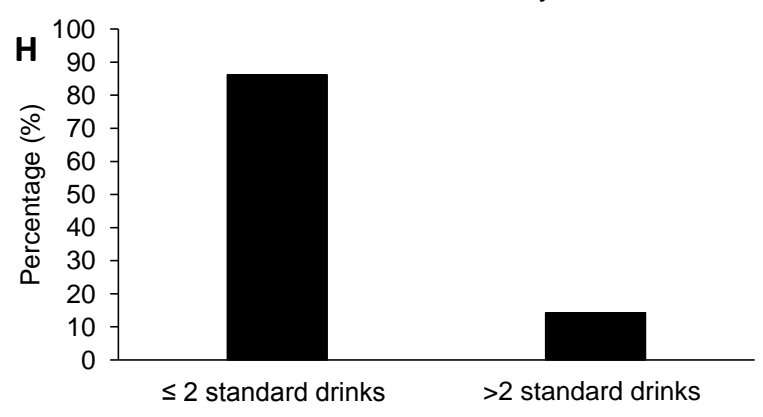




\section{University Library}

\section{- M M N E R VA A gateway to Melbourne's research publications}

Minerva Access is the Institutional Repository of The University of Melbourne

Author/s:

Yiallourou, SR;Maguire, GP;Carrington, MJ

Title:

Sleep quantity and quality and cardiometabolic risk factors in Indigenous Australians

Date:

2020-06-11

Citation:

Yiallourou, S. R., Maguire, G. P. \& Carrington, M. J. (2020). Sleep quantity and quality and cardiometabolic risk factors in Indigenous Australians. JOURNAL OF SLEEP RESEARCH, 30 (2), https://doi.org/10.1111/jsr. 13067.

Persistent Link:

http://hdl.handle.net/11343/275892 